\title{
Sistem Monitoring Pengiriman Alat Kerja Dengan Mengunakan Teknologi CouchDB
}

\author{
M. Hadi Prayitno ${ }^{1, *}$, Achmad Noe'man ${ }^{1}$ \\ ${ }^{1}$ Informatika; Fakultas IImu Komputer; Universitas Bhayangkara Jakarta Raya;Jl. Raya \\ Perjuangan No.18, Margamulya, Bekasi Utara, Kota Bekasi; \\ hadi.prayitno@dsn.ubharajaya.ac.id; achmad.noeman@dsn.ubharajaya.ac.id
}

*Korespondensi: email: hadi.prayitno@dsn.ubharajaya.ac.id

Diterima: 22 Nov 2020; Review: 11 Des 2020; Disetujui: 29 Des 2020; Diterbitkan: 31 Des 2020

\begin{abstract}
CV. BJS is a company engaged in the rental of work tools, especially heavy equipment, and serves in the areas of Java, Sumatra, Kalimantan, Sulawesi and Bali. The Work Tools will be sent using company vehicles. The problem that arises from the delivery process is the unknown presence of delivery vehicles from both the company and the customer side, so customers often complain because there is no certainty about the arrival of the heavy equipment being rented. In this study, 2 applications have been made that can answer company problems. The first application, also known as administrative application, is made for administrative processes that are web-based and will be accessed by internal companies and customers. The second application, an Android-based application used by heavy equipment deliverers, will inform the whereabouts of the vehicle through CouchDB technology which is also used to provide real-time tracking and monitoring of the system.
\end{abstract}

Keywords: work tools, delivery, couchdb

\begin{abstract}
Abstrak
CV. BJS merupakan perusahaan yang bergerak di bidang penyewaan alat kerja, khususnya alat-alat berat, dan melayani di area Jawa, Sumatera, Kalimantan, Sulawesi, dan Bali. Alat Kerja tersebut akan dikirim dengan menggunakan kendaraan perusahaan. Permassalah yang timbul dari proses pengantaran adalah tidak diketahuinya keberadaan kendaraan pengantar baik dari sisi perusahaan ataupun para pelanggan, sehingga pelanggan sering mengeluh karena tidak ada kepastian kedatangan alat berat yang disewa.

Pada penelitian ini, telah dibuat 2 buah aplikasi yang dapat menjawab permasalahan perusahaan. Aplikasi pertama, disebut juga aplikasi administrasi, dibuat untuk proses administrasi yang dibuat berbasis web dan akan diakses oleh internal perusahaan dan pelanggan. Aplikasi kedua, adalah aplikasi berbasis Android yang digunakan oleh para pengantar alat berat, yang akan akan menginformasikan keberadaan kendaraan melakui teknologi CouchDB juga digunakan untuk menyediakan pelacakan dan pemantauan waktu nyata sistem.
\end{abstract}

Kata kunci: alat kerja, pengantaran, couchdb 


\section{Pendahuluan}

CV Berkat Jaya Santosa (CV.BJS) adalah sebuah perusahaan penyedia jasa sewa alat berat untuk proyek di wilayah Jawa, Sumatera, Kalimantan, Sulawesi, dan Bali. Melihat lokasi proyek pelanggan, maka diperlukan sebuah system untuk melacak sekaligus memonitoring status pengiriman barang melalui jasa pengiriman barang yang ada saat ini. CV. BJS harus monitoring setiap pengiriman alat berat yang dilakukannya dari tempat asal sampai ke tempat tujuan yang berguna untuk memastikan dan memantau pergerakan alat berat yang dikirim melalui jalur darat, laut dan udara.

Permasalahan saat ini yang dihadapi adalah belum tersedianya system informasi untuk memonitor keberadaan alat yang dikirim secara real time (Somya, 2018). Saat ini, monitoring pengiriman hanya berdasarkan laporan petugas yang mengantar dan tidak setiap saat pula melaporkan keberadaannya. Dampak dari masalah ini, CV.BJS tidak dapat memberikan informasi yang tepat kepada pelanggan.

Selama proses pengiriman, CV BJS dan atau pelangan dapat memeriksa sampai mana proses pengiriman barang. Banyaknya barang yang dikirimkan menyebabkan proses pengecekan barang kiriman dengan bertanya ke unit kendaraan menjadi lebih sulit. Keadaan ini bertambah sulit karena mengandalkan informasi yang diberikan petugas pengantar barang dengan menggunakan telepon ataupun SMS untuk menginformaikan keberadaan lokasi pengiriman.

Berdasarkan masalah yang telah dijelaskan, maka latar belakang dari penelitian ini adalah membuat sistem monitoring kendaraan secara real time yang dapat diakses langsung oleh CV. BSJ dan pelanggan tanpa selalu meminta informasi. Teknologi real time memungkinkan untuk membuat suatu sistem monitoring dengan jeda waktu yang minimal. Informasi lokasi pengiriman akan langsung diketahui. Teknologi ini kemudian dapat digabungkan dengan perangkat Android sehingga dapat diakses secara mobile oleh siapa saja, di mana saja, dan kapan saja. Maka solusi yang diberikan untuk masalah yang ada adalah dengan membuat sistem

Berdasarkan masalah diatas, maka tujuan penelitian ini membuat monitoring pengiriman alat-alat berat berbasis online dan memberikan kemudahan informasi kepada konsumen dalam melakukan monitoring jasa alat berat melalui online (Kholisho \& Marfuatun, 2019). System monitoring ini adalah system yang dapat memberikan informasi secara real time dan dapat diakses pula oleh siapa saja, di mana saja, dan kapan saja (Noeman \& Handayani, 2019).

Agar lebih terarah, penelitian ini memfokuskan pada pembuatan sistem pelacakan dengan metode extreme programing (Fatoni \& Dwi, 2016), dengan menggunakan menggunakan Android native programming (Java) yang terkoneksi pada database Apache CouchDB dan API Android 19, serta memperhatikan proses bisnis yang ada pada CV. BJS. 


\section{Metode Penelitian}

Pada penelitian ini, penulis menggunakan metode Extreme Programming, Extreme Programming (XP) adalah sebuah pendekatan pengembangan perangkat lunak yang menyederhanakan tahapan dalam proses pengembangan tersebut agar lebih adaptif dan fleksibel. XP bukan hanya berfokus pada coding tetapi meliputi seluruh area pengembangan perangkat lunak. XP mengambil pendekatan 'ekstrim' dalam iterative development. bagi penulis metode inilah yang sangat tepat untuk pengembangan perangkat untuk skala perusahaan (Akbar, 2017).

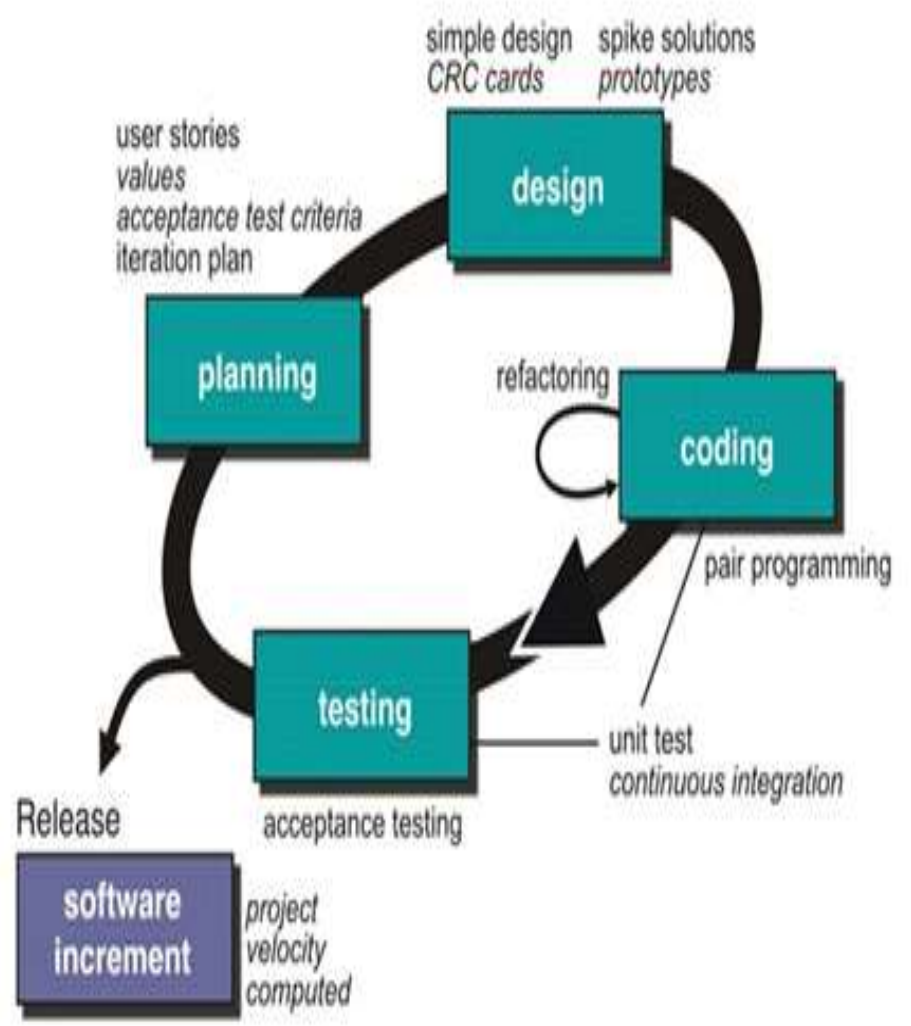

Sumber : Hasil Penelitian (2020)

Gambar 1. Extreme Programming (Jeffries, 2018)

\subsection{Planning}

Tahapan ini bertujuan untuk memahami kebutuhan-kebutuhan dengan memberikan umpan balik pelanggan tentang aspek teknis bagaimana masalah bisa dipecahkan, atau tidak dapat dipecahkan. Penulis melakukan wawancara kepada pemilik usaha dan mendapatkan perencanaan dari sistem yang akan dibuat nantinya, Dari hasil wawancara yang penulis peroleh dari CV. BJS penulis mulai mendapat gambaran untuk melakukan tahap selanjutnya yaitu perancangan sistem informasi CV. BJS pada tahap design yang ada di metode extereme 
programming ini. Gambaran tersebut dapat dijabarkan dalam sebuah Analisa kebutuhan sebagai berikut

Fungsional :

a. Sistem dapat mengidentifikasi data pelanggan

b. Sistem dapat mengidentifikasi alat berat

c. Sistem membutuhkan informasi keberadaan alat berat dan status pengiriman dari ekspedisi melalui telepon seluler.

d. Sistem membutuhkan data kriteria alat, jarak dan paket pengiriman Non Fungsional

e. Sistem dapat diakses 24 jam sehari, 7 hari seminggu

f. Sistem dapat dijalankan menggunakan sistem operasi Android dengan versi API minimal 19

g. Sistem harus bisa menyimpan semua data yang dimasukkan, baik detail alat bert yang dikirim, lokasi pemesan, dan hasil track lokasi petugas pengiriman

\subsection{Design}

Tahap ini didasari pada tahap planning yang telah dikumpulkan sebelumnya dengan menghindari kerangkapan system. Aktivitas mendesain ini menggunakan diagram UML. Berikut use case dari diagram UML sistem informasi monitoring pengiriman barang di CV. BJS

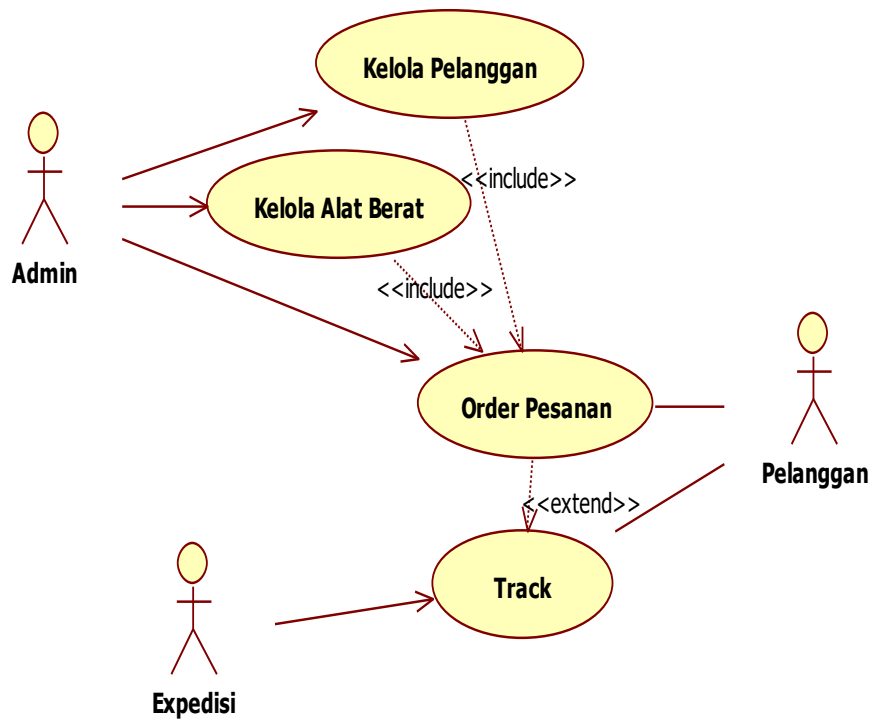

Sumber : Hasil Penelitian (2020)

Gambar 2. Use Case System

Pada Use Case diatas, menggambarkan 3 buah actor dengan scenario sebagai berikut : 
Table 1. Screnario Use Case

\begin{tabular}{llll}
\hline No & Actor & Use Case yang terhubung & Akses \\
\hline 1 & Admin & Kelola Pelangga & Create-Read-Update-Delete \\
\hline & & Kelola Alat Berat & Create-Read-Update-Delete \\
\hline & & Order Pesanan & Create-Read-Update-Delete \\
\hline 2 & Expedisi & Track & Create-Read-Update-Delete \\
\hline 3 & Pelanggan & Order Pesanan & Read \\
\hline & & Track & Read \\
\hline
\end{tabular}

Sumber : Hasil Penelitian (2020)

Disamping itu, di lakukan design untuk jaringan komunikasi dan secara umum dapat di gambarkan sebagai berikut :

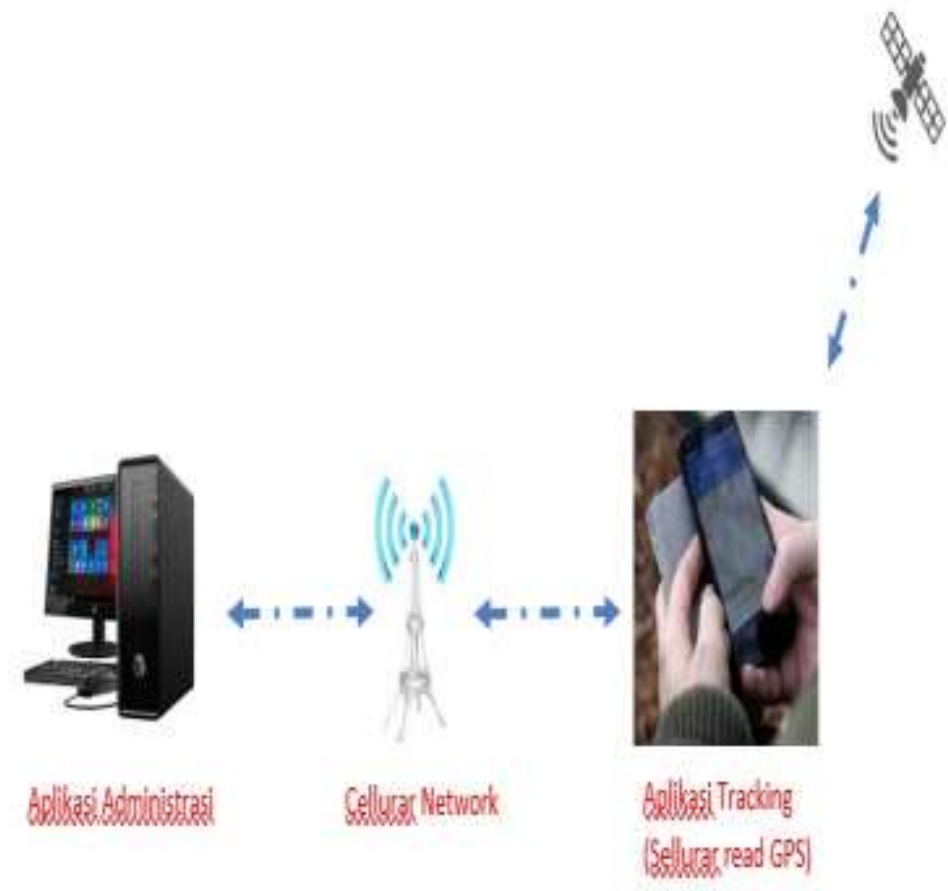

Sumber : Hasil Penelitian (2020)

Gambar 3. Rancangan Komunikasi Jaringan

\subsection{Coding}

Implementasi dari usulan design sistem akan dilakukan pengkodean atau coding untuk dibuatkan aplikasinya di sini penulis menggunakan sublime text editor, php sebagai bahasa pemrogramman sisi server atau server side, Hyper Text Markup Language (HTML) sebagai 
bahasa pemrogramman website, Cascading Style Sheet (CSS) untuk mengatur layout website agar terlihat presisi dan menarik, JavaScript untuk memberikan animasi-animasi pada halaman website. XAMPP sebagai alat mini web server untuk database nya. Hasil dari coding ini merupakan produk yang diharapkan dapat diimplementasikan pada bisnis CV. BJS (Informatika et al., 2014).

\subsection{Testing}

Setelah pengkodean atau coding selesai selanjutnya penulis melakukan pengujian dengan metode blackbox untuk menguji setiap fungsional dari setiap program berjalan dengan baik sesuai pada tahapan design dan pengkodean atau coding yg sudah dikerjakan sebelumnya. Testing ini bertujuan untuk mengetahui desain bug, menghilangkan kekurangan dan kelemahan system.

\section{Hasil dan Pembahasan}

Sistem monitoring terdiri dari 2 aplikasi utama yaitu (1) Aplikasi administrasi, aplikasi yang diperuntukkan pada bagian yang bertanggung jawab terhadap proses administrasi pengiriman, dan (2) Aplikasi Tracking, aplikasi yang diperuntukkan pada bagian expedisi, petugas yang mengantar alat kerja dimaksud.

\subsection{Aplikasi Administrasi}

Aplikasi ini hanya diperuntukan proses-proses administrasi, berupa form-form input data yang dapat dipilih di dalam menu utama.

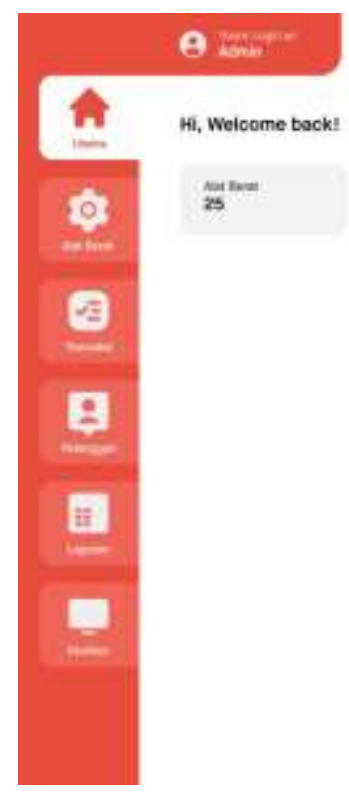

Sumber : Hasil Penelitian (2020)

Gambar 4. Menu Utama Aplikasi Adminisrasi

Hasil dari aplikasi administrasi ini berisikan form pelanggan, alat berat yang disewakan, transaksi dan cetak laporan monitoring pengiriman alat berat ke pelanggan. 


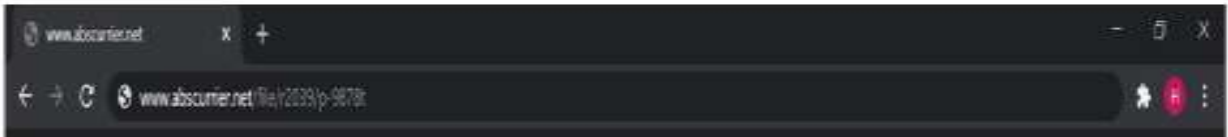

Nonitaing Trading

Periode: $0100 \mathrm{ct} 2000-050 \mathrm{ct} 20 \mathrm{e}:$

\begin{tabular}{|c|c|c|c|c|c|c|c|c|}
\hline Custtrter & Onder & Stopirg Date & liten & aty & Destration & Psstion & Date & Strats \\
\hline D54535 P. Keu Dabon & DE67764C & $00 \cdot 00-20$ & 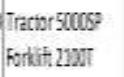 & & diesen & Gegot & $00-0 c+20$ & Finish \\
\hline 504532 F. Hoiran & ntr5565L4 & $15-000-20$ & Touar Crain 2000 & & Palanbats: & Merak & $007-0 \mathrm{ct}-20$ & On Progress \\
\hline
\end{tabular}

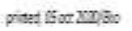

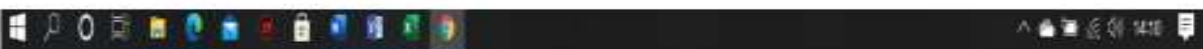

Sumber : Hasil Penelitian (2020)

Gambar 5. Cetakan monitoring Tracking

\subsection{Aplikasi Tracking}

Aplikasi tracking digunakan oleh bagian expedisi yang mengantar alat kerja ke tujuan pengiriman, aplikasi ini berfungsi sebagai pengganti GPS tracker berbasis SMS yang dalam memberikan posisi pengiriman yang dilakukan oleh petugas expedisi

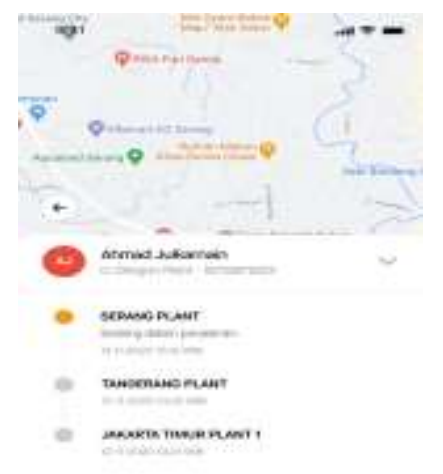

Sumber : Hasil Penelitian (2020)

Gambar 6. Aplikasi Tracking 
Sistem monitoring tracking ini memanfaatkan GPS perangkat Android sehingga dapat diketahui posisi pengiriman. Petugas pengiriman wajib menekan tombol "Kirim Posisi Sekarang", maka aplikasi akan mengirim posisinya ke database CouchDB [8] yang terrelasi dengan aplikasi administrasi, hasilnya pada aplikasi administrasi dapat di cetak posisi petugas pengiriman dan sekaligus dilakukan monitoring posisi petugas pengiriman.

Konsep real time yang ditawarkan sistem monitoring tracking ini dengan memanfaatkan changes listener pada CouchDB (atau real time database lainnya) dan google API. Change listener akan mengirim pesan ke sistem saat terjadi perubahan pada record di dalam database. Maka saat aplikasi tracking melakukan update record tersebut.

\subsection{Pengujian Sistem}

Pengujian system dilakukan dengan menguji coba semua fungsi dengan membandingkan hasil pengujian dengan hasil yang diharapkan.

Tabel 2. Hasil Pengujian Black Box

\begin{tabular}{|c|c|c|c|}
\hline No & Deskripsi & Hasil yang diharapkan & $\begin{array}{l}\text { Status } \\
\text { pengujian }\end{array}$ \\
\hline 1 & $\begin{array}{l}\text { Menguji koneksi } \\
\text { aplikasi tracking } \\
\text { dengan database }\end{array}$ & $\begin{array}{l}\text { Aplikasi akan melakukan } \\
\text { serangkaian proses untuk } \\
\text { memulai tracking service, } \\
\text { sekaligus membuat record } \\
\text { pada CouchDB }\end{array}$ & Valid teruji \\
\hline 2 & $\begin{array}{l}\text { Penguji membuat } \\
\text { laporan dari aplikasi } \\
\text { tracking }\end{array}$ & $\begin{array}{l}\text { Laporan terkirim ke database } \\
\text { CouchDB dan tersimpan } \\
\text { dalam SQLite }\end{array}$ & Valid teruji \\
\hline 3 & $\begin{array}{l}\text { Penguji melakukan } \\
\text { monitoring kendaraan } \\
\text { secara real time saat } \\
\text { aplikasi mengirim } \\
\text { pesan posisi terkini }\end{array}$ & $\begin{array}{l}\text { Posisi terkini yang terkoneksi } \\
\text { dengan peta Google Maps, } \\
\text { lalu di tampilkan pada } \\
\text { halaman tracking }\end{array}$ & Valid teruji \\
\hline
\end{tabular}

Sumber : Hasil Penelitian (2020) 
Hasil blackbox testing pada Tabel 2 diatas menunjukkan bahwa setiap fungsi pada system adalah valid teruji, berarti system yang dibuat sudah sesuai dengan kebutuhan CV BJS.

\section{Kesimpulan}

Berdasarkan penelitian yang dilakukan, didapatkan kesimpulan yaitu untuk membuat sebuah sistem monitoring pengiriman alat kerja ke tempat lokasi pelanggan.. Sistem monitoring kendaraan yang dibuat pada penelitian ini dapat memberikan laporan data lokasi kendaraan secara real time dan dapat diakses dengan cepat dan akurat saat dibutuhkan, dengan menggunakan GPS yang ada di Android.

Sistem informai monitoring pengiriman ini akan diimplementasikan ke dalam 2 aplikasi. Aplikasi pertama adalah aplikasi yang digunakan oleh internal CV. BJS. Aplikasi ini bersifat administrative traksasi, sekaligus memverifikasi keberadaan pengiriman yang selanjutkan dilakukan proses monitoring. Aplikasi kedua adalah aplikasi yang akan diberikan kepada petugas pengiriman, yang akan mengirim informasi mengenai keberadaan barang yang dikirim.

Guna mempercepat system tracking ini dapat diimplementasikan, penulis meggunakan edtoe Extreme programing, dengan demikian layanan pengiriman alat kerja yang dipesan dapat cepat berjalan.

Dengan system monitoring ini, perusahaan dapat mengetahui posisi alat kerja yang dikirim Selain itu sistem monitoring yang baru juga memiliki sistem pelaporan dan verifikasi barang yang terintegrasi, antara petugas aplikasi administrasi dan aplikasi tracking, dengan demikian dapat membantu para pengambil keputusan untuk dapat meningkatkan pelayanan.

\section{Daftar Pustaka}

Akbar, A. S. (2017). Rancang Bangun Sistem Informasi Administrasi Hotel Dengan Metode Extreme Programming. Jurnal Disprotek, 8(2), 26-41. https://ejournal.unisnu.ac.id/JDPT/article/view/540/857

C. Anderson, J. Lehnardt, dan N. Slater. CouchDB: (2013). The Definitive Guide. O'Reilly Media.

Cisco (2017) Internet of Things (IoT) - Cisco, Online. Tersedia pada:

http://www.cisco.com/c/en/us/solutions/int ernet-of-things/overview.html

(Diakses: 20 Maret 2019).

Fatoni, A., \& Dwi, D. (2016). Rancang Bangun Sistem Extreme Programming Sebagai Metodologi Pengembangan Sistem. Prosisko, 3(1), 1-4. http://ejurnal.Ippmunsera.org/index.php/PROSISKO/article/view/116

Informatika, J. T., Teknik, F., Bhayangkara, U., \& Raya, J. (2014). Sistem Informasi Penjualan Batu Kapur Menggunakan Metode Technology Acceptance Model (Tam) Pada Cv. Xyz Berbasis Web. Jurnal Sistem Informasi Universitas Suryadarma, 153-174. https://doi.org/10.35968/jsi.v6i2.323

Jeffries, R. E., 2018. X Programming. [Online] Available at: 
http://xprogramming.com/index.php?s=values+of+extreme+programming [Accessed 1108 2019].

Kholisho, Y. N., \& Marfuatun. (2019). EDUMATIC: Jurnal Pendidikan Informatika. Jurnal Pendidikan Informatika, 3(2), 99-108. https://doi.org/10.29408/edumatic.v4i2.2686

Noeman, A., \& Handayani, D. (2019). Perancangan Sistem Informasi Document Monitoring Sampling Product Dengan Metode Prototype. 12(3), 219-229. https://doi.org/10.30998/faktorexacta.v12i3.4678

Safaat, N. H., (2015). Rancang Bangun Aplikasi Multiplatform. Bandung: Informatika.

Somya, R. (2018). Sistem Monitoring Kendaraan Secara Real Time Berbasis Android menggunakan Teknologi CouchDB di PT. Pura Barutama. Jurnal Nasional Teknologi Dan Sistem Informasi, 4(2), 53-60. https://doi.org/10.25077/teknosi.v4i2.2018.53-60 